\title{
Photoluminescence of erbium-implanted GaN and in situ-doped GaN:Er
}

\author{
D. M. Hansen, ${ }^{\text {a) }}$ R. Zhang, N. R. Perkins, S. Safvi, L. Zhang, K. L. Bray, and T. F. Kuech \\ Department of Chemical Engineering, University of Wisconsin, Madison, Wisconsin 53706
}

(Received 19 November 1997; accepted for publication 11 January 1998)

\begin{abstract}
The photoluminescence of in situ-doped GaN:Er during hydride vapor phase epitaxy was compared to an Er-implanted GaN sample. At $11 \mathrm{~K}$, the main emission wavelength of the in situ-doped sample is shifted to shorter wavelengths by $2.5 \mathrm{~nm}$ and the lifetime is $2.1 \pm 0.1 \mathrm{~ms}$ as compared to $2.9 \pm 0.1$ ms obtained for the implanted sample. The $295 \mathrm{~K}$ band edge luminescence of the in situ-doped sample was free of the broad band luminescence centered at $500 \mathrm{~nm}$ which dominated the spectrum of the implanted sample. Reversible changes in the emission intensity of the in situ-doped sample upon annealing in a $\mathrm{N}_{2}$ versus a $\mathrm{NH}_{3} / \mathrm{H}_{2}$ ambient indicate the probable role of hydrogen in determining the luminescence efficiency of these samples. (C) 1998 American Institute of Physics.
\end{abstract} [S0003-6951(98)02010-5]

The rare-earth element erbium in the trivalent state $\left(\mathrm{Er}^{3+}\right)$ has received considerable attention since the ${ }^{4} I_{13 / 2}$ $\rightarrow{ }^{4} I_{15 / 2}$ transition at $1540 \mathrm{~nm}$ coincides with a minimum in loss in silica optical fibers. ${ }^{1}$ This transition occurs between energy levels within the shielded $4 f$ electron shell, making the optical transitions of $\mathrm{Er}^{3+}$ sharp, as well as relatively insensitive to temperature and host affects. ${ }^{2}$ These luminescence properties make erbium-doped semiconductors an appealing material system for application in optoelectronic devices.

One problem which plagues the development of a practical erbium-doped semiconductor device is the pronounced temperature quenching of the rare-earth luminescence within most semiconductor hosts. Favennec et al. discovered that quenching of the rare-earth luminescence was reduced in wide band-gap semiconductor hosts. ${ }^{3}$ This discovery has lead to several investigations of Er-implanted GaN. ${ }^{4-12} \mathrm{GaN}$ is a wide band-gap III-V semiconductor useful as a short wavelength emitter and detector. ${ }^{13}$ Previous investigations of Er luminescence in $\mathrm{GaN}$ : $\mathrm{Er}$ have been promising with most researchers finding only an $\sim 50 \%$ decrease in photoluminescence intensity over the temperature range $6-300 \mathrm{~K}^{4,8,9,11}$ This is a significant improvement over the two-to-three order of magnitude decrease of Er luminescence intensity in GaAs:Er. ${ }^{2}$

The studies performed on GaN:Er so far have principally focused on Er implanted into GaN. The large mass of the $\mathrm{Er}$ implant species limits this technique to the formation of thin layers of GaN:Er with a high amount of residual implantrelated damage. In this letter, we report a photoluminescence study of in situ-doped GaN:Er during hydride vapor phase epitaxy (HVPE) using elemental $\mathrm{Er}$ as the in situ dopant and Er implanted into nominally undoped $\mathrm{GaN}$ also grown by HVPE. HVPE is an established technique for GaN growth and is capable of providing high growth rates and thick GaN layers. ${ }^{13,14}$ The in situ doping of GaN with Er during HVPE growth should result, therefore, in thick, uniformly doped layers. Low temperature $\mathrm{Er}^{3+}$ luminescence of the in situdoped sample is observed with the peak intensity at $\mathbf{1 5 3 6 . 5}$

${ }^{\text {a)} E l e c t r o n i c ~ m a i l: ~ d h a n s e n @ a m p s . c h e . w i s c . e d u ~}$ $\mathrm{nm}$ and an $11 \mathrm{~K}$ lifetime of $2.1 \pm 0.1 \mathrm{~ms}$. The $\mathrm{Er}^{3+}$ luminescence was no longer detectable above $150 \mathrm{~K}$ so the temperature quenching to room temperature could not be determined. The band edge luminescence spectra showed considerable structure between 380 and $390 \mathrm{~nm}$ at $11 \mathrm{~K}$ evolving into a broad band centered at $390 \mathrm{~nm}$ at $295 \mathrm{~K}$.

In situ-doped GaN:Er was grown in a horizontal HVPE reactor. The nitrogen precursor was $\mathrm{NH}_{3}$. A Ga:Er solution held in a quartz boat at $880^{\circ} \mathrm{C}$ served as both the group III and dopant source. According to the phase diagram, the binary $\mathrm{Ga}-\mathrm{Er}$ system forms a miscible liquid from 0 to 27 wt $\%$ Er at $T=880^{\circ} \mathrm{C}$. The transport of Er to the growing $\mathrm{GaN}$ crystal structure occurred most probably via $\mathrm{ErCl}_{3}$. This assumption was based on theoretical work which showed that the stability of other gas phase rare-earth chlorides followed the trend $\mathrm{RECl}_{3}>\mathrm{RECl}_{2}>\mathrm{RECl} .{ }^{15}$ Although data regarding the vapor pressure of this species were scarce, one source did indicate that $\mathrm{ErCl}_{3}$ has a pressure of 2 Torr at $T=950{ }^{\circ} \mathrm{C} .{ }^{16}$ The Ga:Er boat was kept at a lower temperature, but this datum indicates that $\mathrm{ErCl}_{3}$ probably had a significant vapor pressure even at $880{ }^{\circ} \mathrm{C}$. A GaN:Er layer, 20 $\mu \mathrm{m}$ thick, was grown at a V/III ratio of 30 and a substrate temperature of $1030{ }^{\circ} \mathrm{C}$. SIMS was performed on the in situdoped sample and revealed a peak Er concentration of 2 $\times 10^{19}$ atoms $/ \mathrm{cm}^{-3}$ at $0.1 \mu \mathrm{m}$ falling to a steady concentration of $1 \times 10^{18}$ atoms $/ \mathrm{cm}^{-3}$ through the remainder of the layer.

The implantation samples were nominally undoped GaN grown on (0001) sapphire by HVPE as previously reported. ${ }^{14}$ Prior to ion implantation the band edge luminescence spectra at $11 \mathrm{~K}$ showed a dominant structure at $357.2 \mathrm{~nm}(3.472 \mathrm{eV})$. Er was implanted into $\mathrm{GaN}$ at $300 \mathrm{keV}$ with a dose of 2 $\times 10^{14}$ atoms $/ \mathrm{cm}^{2}$. Secondary ion mass spectrometry (SIMS) data indicate that the peak Er concentration was 5.3 $\times 10^{19}$ atoms $/ \mathrm{cm}^{3}$ at a depth of $33.1 \mathrm{~nm}$. Oxygen was coimplanted into the $\mathrm{GaN}$ at $40 \mathrm{keV}$ and a dose of 2 $\times 10^{15}$ atoms $/ \mathrm{cm}^{2}$. SIMS was not used to determine the $\mathrm{O}$ concentration, but calculations estimate a peak concentration of $3.4 \times 10^{20}$ atoms $/ \mathrm{cm}^{3}$ at a depth of $54.0 \mathrm{~nm}$. As reported previously, oxygen enhances or activates the Er luminescence in the GaN host. ${ }^{4-6,8-11}$ The samples showed no band 


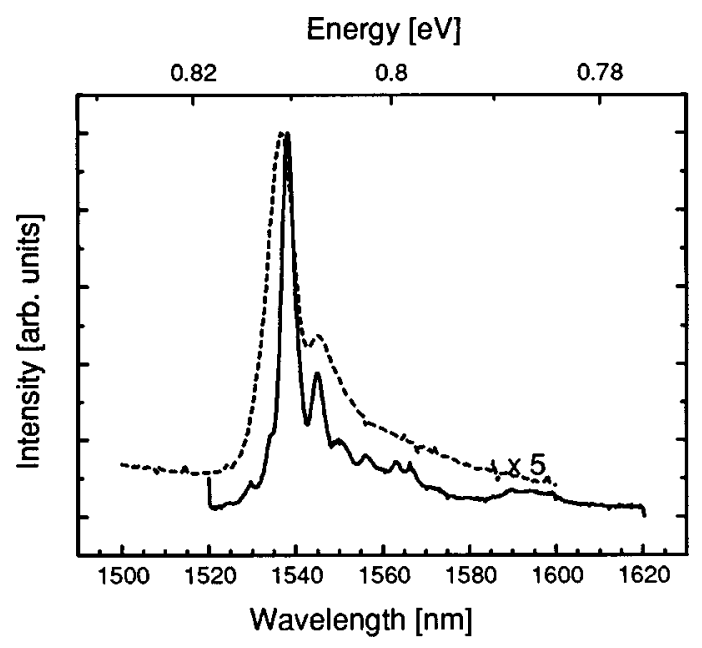

FIG. 1. $11 \mathrm{~K}$ photoluminescence spectra of the $\mathrm{Er}^{3+}$ emission obtained with $488 \mathrm{~nm}$ excitation. The dashed line is from in situ-doped GaN:Er grown by HVPE. The solid line is for $\mathrm{Er}$ and $\mathrm{O}$ coimplanted into GaN grown by HVPE.

edge or Er related luminescence prior to annealing. The annealing conditions were $800{ }^{\circ} \mathrm{C}$ for $0.5 \mathrm{~h}$ in a flowing $\mathrm{NH}_{3} / \mathrm{H}_{2}$ ambient. ${ }^{9}$

$\mathrm{Er}^{3+}$ luminescence was excited with an average power of $100 \mathrm{~mW}$ from the $488 \mathrm{~nm}$ line of an $\mathrm{Ar}$ ion laser. The sample temperature was controlled between 11 and $295 \mathrm{~K}$ with a variable temperature cryostat. The $\mathrm{Er}^{3+}$ luminescence was dispersed with a $1.5 \mu \mathrm{m}$ blazed grating housed in a $1 \mathrm{~m}$ monochromator. The signal was detected by a liquid $\mathrm{N}_{2}$ cooled Ge detector and standard lock-in techniques. Lifetime measurements were made with a faster liquid $\mathrm{N}_{2}$ cooled $\mathrm{Ge}$ detector and digital oscilloscope. Band edge GaN spectra were excited with $2 \mathrm{~mW}$ of the $325 \mathrm{~nm}$ line of a $\mathrm{He}-\mathrm{Cd}$ laser. Luminescence was dispersed with a $400 \mathrm{~nm}$ blazed grating housed in the same monochromator and detected with a photomultiplier tube. The resolution of the system was at least $1.5 \mathrm{~nm}$ and the spectra have not been corrected for system response.

Figure 1 provides the $11 \mathrm{~K}$ spectra of the $\mathrm{Er}^{3+}$ emission for both the in situ-doped and ion-implanted GaN:Er. The spectra have been normalized to the peak emission wavelength for ease of comparison. The peak luminescence intensity of the in situ-doped sample is a factor of 5 weaker and the peak wavelength is shifted $2.5 \mathrm{~nm}$ compared to the $\mathrm{Er}^{3+}$ emission from the implanted sample. The reduced luminescence intensity of the in situ-doped sample needs to be investigated further. One possibility is that the excitation mechanism is different between the two samples. Currently, the excitation mechanism is not known, but some researchers have suggested a trap-mediated pathway for Er-implanted GaN. ${ }^{17}$ It is also conceivable that the $488 \mathrm{~nm}$ light directly excites the Er ions. ${ }^{6}$

The shift in the location of the peak intensity implies that the optically active $\mathrm{Er}^{3+}$ center in the two samples is different. This result is supported by the measurement of the $11 \mathrm{~K}$ lifetime at the peak emission wavelength. The lifetime of the $\mathrm{Er}^{3+}$ emission in the in situ-doped sample was determined to be $2.1 \pm 0.1 \mathrm{~ms}$. The lifetime of the $\mathrm{Er}^{3+}$ emission in the implanted sample was determined to be $2.9 \pm 0.1 \mathrm{~ms}$, consistent with previous reports. ${ }^{11}$ Although the bonding environDownloaded 04 Jan 2007 to 128.104.30.229. Redistribution subje

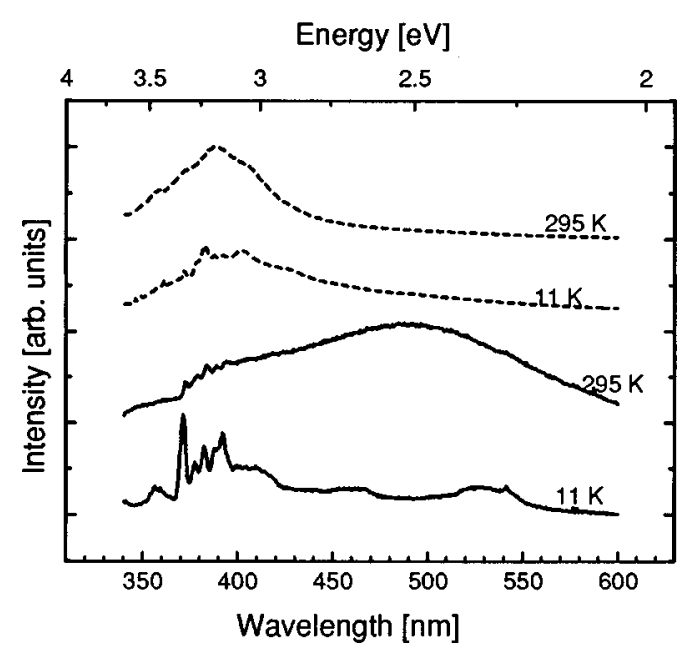

FIG. 2. GaN band edge spectra obtained with $325 \mathrm{~nm}$ excitation. The dashed lines are for the in situ-doped GaN:Er. The solid lines are for the GaN:Er implanted.

ment of the optically active $\mathrm{Er}^{3+}$ ions in both samples is unknown at this time these results indicate that they are different. In the implanted sample, the $\mathrm{Er}^{3+}$ is presumably associated with some number of oxygen atoms, however, in the in situ-doped sample the associated ligand is unknown since no codopants were intentionally added to the reactor.

The temperature dependence of the $\mathrm{Er}^{3+}$ emission intensity in the in situ-doped sample could not be determined due to the weak optical signal over the measured temperature range. Above $150 \mathrm{~K}$, the $\mathrm{Er}^{3+}$ emission could no longer be detected, however, the peak emission wavelength shifted less than $0.2 \mathrm{~nm}$ from 11 to $150 \mathrm{~K}$, which is consistent with emission from the shielded $4 f$-shell electrons. The apparent increased temperature quenching from in situ-doped $\mathrm{GaN}: \mathrm{Er}$ is consistent with what researchers have discovered for GaN:Er grown by metalorganic molecular beam epitaxy. ${ }^{18}$ For the implanted sample the peak intensity decreased by a factor of 4 and the integrated intensity decreased by a factor of 1.8 over the temperature range 11-295 K, consistent with previous reports. ${ }^{4,8,9,11,12}$ The peak emission lifetime at 295 $\mathrm{K}$ was determined to be $2.3 \pm 0.1 \mathrm{~ms}$ which is similar to the value reported by Torvik et al. ${ }^{9}$

The band edge spectra of the two samples are provided in Fig. 2 for temperatures of 11 and 295 K. Both band edge spectra show a significant amount of structure around 390 $\mathrm{nm}$ at $11 \mathrm{~K}$. These spectra indicate that both samples have states within the semiconductor band gap. The difference in band edge emission for the two samples becomes more obvious at a measurement temperature of $295 \mathrm{~K}$. The band edge spectrum of the in situ-doped GaN:Er shows only one structure centered at $390 \mathrm{~nm}$. On the other hand, the ionimplanted sample shows a broad defect band centered at 500 $\mathrm{nm}$ indicating the presence of deep levels. This result could indicate a reduction in nonradiative pathways from deep level states for the in situ-doped sample compared to the ion-implanted sample, however, further work needs to be performed before this can be stated with certainty.

An annealing study was performed on the in situ-doped sample to determine if the $\mathrm{Er}^{3+}$ luminescence could be improved. The sample was annealed first at $800{ }^{\circ} \mathrm{C}$ for $0.5 \mathrm{~h}$ in flowing $\mathrm{N}_{2}$. Figure 3 shows that the $\mathrm{Er}^{3+}$ emission is identiflowing $\mathrm{N}_{2}$. Figure 3 shows that the Er emission is identi-
to AIP license or copyright, see http://apl.aip.org/apl/copyright.jsp 


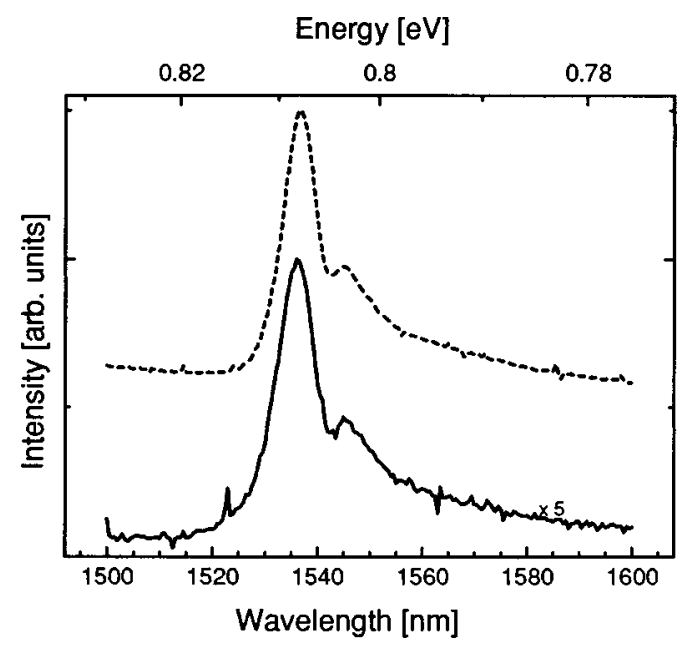

FIG. 3. $11 \mathrm{~K}$ photoluminescence spectra of the $\mathrm{Er}^{3+}$ emission obtained with $488 \mathrm{~nm}$ excitation. The dashed line is for the as-grown in situ-doped $\mathrm{GaN}$ :Er. The solid line is after annealing at $800{ }^{\circ} \mathrm{C}$ in $\mathrm{N}_{2}$ for $0.5 \mathrm{~h}$.

cal in shape, but a factor of 5 weaker than the as-grown sample. The same sample was then annealed at $800^{\circ} \mathrm{C}$ in a $\mathrm{NH}_{3}$ atmosphere for $0.5 \mathrm{~h}$. The resulting $\mathrm{Er}^{3+}$ photoluminescence spectrum is identical to that shown in Fig. 3, however, the intensity returned to approximately the same value as that obtained for the as-grown sample. This result could be interpreted as an effect due to the presence of hydrogen. Hydrogen is known to passivate defects and impurities in GaN. In particular, hydrogen can effectively passivate acceptors in $\mathrm{GaN}$ leading to complications in obtaining $p$-type samples. In order to investigate this potential effect of hydrogen, a similar annealing study was performed on the implanted sample, but a similar trend was not discovered. In this case each anneal resulted in continually increasing photoluminescence intensity without affecting the spectrum appearance. One possible explanation for this observation is that the original implant annealing conditions were not optimized, therefore, further annealing optically activated more $\mathrm{Er}^{3+}$ ions regardless of the annealing ambient. Implant activation in $\mathrm{GaN}$, in general, has not been studied in detail. Further studies have to be performed in order to determine if passivation or some other mechanism is involved in the reversible intensity changes of the $\mathrm{Er}^{3+}$ luminescence for the in situdoped sample.

In summary, we report $\mathrm{Er}^{3+}$ luminescence from in situdoped and ion-implanted GaN:Er. The $11 \mathrm{~K}$ spectra and lifetime measurements are slightly different than the $\mathrm{Er}^{3+}$ emission from an implanted sample indicating a different optically active center or environment. The $295 \mathrm{~K}$ band edge luminescence spectra of the in situ-doped sample was free of the broad band luminescence at $500 \mathrm{~nm}$ which dominated the implanted sample band edge spectrum. Annealing of the in situ-doped $\mathrm{GaN}$ : $\mathrm{Er}$ in $\mathrm{N}_{2}$ weakened the $\mathrm{Er}^{3+}$ luminescence intensity, however, the intensity returned after subsequent annealing in a $\mathrm{NH}_{3} / \mathrm{H}_{2}$ ambient. Future work will concentrate on the possible effect of hydrogen on the $\mathrm{Er}^{3+}$ luminescence as well as increasing the $\mathrm{Er}^{3+}$ intensity in the in situdoped sample.

This work was supported by the National Science Foundation Division of Materials Research and by the ARPAURI on Visible Light Emitters. D. M. Hansen would like to acknowledge the financial support of the National Science Foundation in the form of a Graduate Research Fellowship. Facilities supported by the National Science Foundation UW-MRSEC is gratefully acknowledged.

${ }^{1}$ T. Miya, Y. Terunuma, T. Hosaka, and T. Miyashita, Electron. Lett. 15, 106 (1979).

${ }^{2}$ S. Hufner, Optical Spectra of Transparent Rare-Earth Ions (Academic, New York, 1978).

${ }^{3}$ P. N. Favennec, H. L'Haridon, M. Salvi, D. Moutonnet, and Y. Le Guillou, Electron. Lett. 25, 718 (1989).

${ }^{4}$ R. G. Wilson, R. N. Schwartz, C. R. Abernathy, S. J. Pearton, N. Newman, M. Rubin, T. Fu, and J. M. Zavada, Appl. Phys. Lett. 65, 992 (1994).

${ }^{5}$ C. H. Qiu, M. W. Leksono, J. I. Pankove, J. T. Torvik, R. J. Feuerstein, and F. Namavar, Appl. Phys. Lett. 66, 562 (1995).

${ }^{6}$ S. J. Pearton, C. R. Abernathy, J. D. MacKenzie, R. N. Schwartz, R. G. Wilson, J. M. Zavada, and R. J. Shul, Mater. Res. Soc. Symp. Proc. 422, 47 (1996).

${ }^{7}$ E. Silkowski, Y. K. Yeo, R. L. Hengehold, B. Goldenberg, and G. S. Pomrenke, Mater. Res. Soc. Symp. Proc. 422, 69 (1996).

${ }^{8}$ J. M. Zavada, R. G. Wilson, R. N. Schwartz, J. D. MacKenzie, C. R. Abernathy, S. J. Pearton, X. Wu, and U. Hommerich, Mater. Res. Soc. Symp. Proc. 422, 193 (1996).

${ }^{9}$ J. T. Torvik, R. J. Feuerstein, C. H. Qiu, M. W. Leksono, J. I. Pankove, and F. Namavar, Mater. Res. Soc. Symp. Proc. 422, 199 (1996).

${ }^{10}$ J. T. Torvik, R. J. Feuerstein, J. I. Pankove, C. H. Qiu, and F. Namavar, Appl. Phys. Lett. 69, 2098 (1996).

${ }^{11}$ J. T. Torvik, C. H. Qiu, R. J. Feuerstein, J. I. Pankove, and F. Namavar, J. Appl. Phys. 81, 6343 (1997).

${ }^{12}$ S. Kim, S. J. Rhee, D. A. Turnbull, E. E. Reuter, X. Li, J. J. Coleman, and S. G. Bishop, Appl. Phys. Lett. 71, 231 (1997).

${ }^{13}$ S. Strite and H. Morkoç, J. Vac. Sci. Technol. B 10, 1237 (1992).

${ }^{14}$ N. R. Perkins, M. N. Horton, Z. Z. Bandic, T. C. McGill, and T. F. Kuech, Mater. Res. Soc. Symp. Proc. 395, 243 (1996).

${ }^{15}$ K. S. Krasnov and T. G. Danilova, High Temp. 7, 1131 (1969).

${ }^{16}$ The Rare Earths, edited by F. H. Spedding and A. H. Daane (Wiley, New York, 1961).

${ }^{17}$ S. Kim, S. J. Rhee, D. A. Turnbull, X. Li, J. J. Coleman, and S. G. Bishop, Mater. Res. Soc. Symp. Proc. 468, 131 (1997).

${ }^{18}$ J. D. MacKenzie, C. R. Abernathy, S. J. Pearton, U. Hommerich, X. Wu, R. N. Schwartz, R. G. Wilson, and J. M. Zavada, J. Cryst. Growth 175/ 176, 84 (1997). 